\title{
Comparative evaluation of fuzzy logic and genetic algorithms models for portfolio optimization
}

\author{
Heidar Masoumi Soureh $^{\mathbf{a}^{*}}$ and Gholamreza Farsad Amanollahi ${ }^{\mathrm{b}^{*}}$
}

${ }^{a}$ School of Financial Management, International Islamic Azad Unit, University, Qeshm, Iran

${ }^{b}$ Assistant Professor, School of Economic and Accounting, Central Branch, Islamic Azad University, Tehran, Iran

\section{H R O N I C L E}

Article history:

Received: October 1, 2016

Received in revised format: No-

vember 16, 2016

Accepted: February 2, 2017

Available online:

February 3, 2017

Keywords:

Fuzzy logic

Genetic algorithms

Profits optimization

Portfolio

\section{A B S T R A C T}

Selection of optimum methods which have appropriate speed and precision for planning and decision-making has always been a challenge for investors and managers. One the most important concerns for them is investment planning and optimization for acquisition of desirable wealth under controlled risk with the best return. This paper proposes a model based on Markowitz theorem by considering the aforementioned limitations in order to help effective decisionsmaking for portfolio selection. Then, the model is investigated by fuzzy logic and genetic algorithms, for the optimization of the portfolio in selected active companies listed in Tehran Stock Exchange over the period 2012-2016 and the results of the above models are discussed. The results show that the two studied models had functional differences in portfolio optimization, its tools and the possibility of supplementing each other and their selection.

\section{Introduction}

Management of portfolio of each company means to analyze weaknesses, strengths and opportunities associated with a wide range of financial activities of that company. The main step in the analysis and management of the portfolio is to find a combination of portfolio so that it could meet the investors' demand. Determination of the optimum portfolio depends on the context of the companies' activities and the investors objectives. In some companies the goals of investment are gaining profits and providing capital for future activities such as expansion of new sections, establishing branches, etc. If investment in such companies is not executed properly, company's current activities and credibility will suffer significantly. Therefore, evaluation of the financial markets' risk and stock returns for the optimum portfolio determination are necessary. In some other companies profit gain is not the only objective and it is important for them to invest in such a way that they could meet their commitments in future, maintain their credibility and continue their activities for the competitive market. So the simultaneous assessment and management of investment risk and optimum choice selection in financial markets in * Corresponding author. Tel.: +98912549385

E-mail address: hmsmasoumi@yahoo.com (H. Masoumi soureha)g.f1966@yahoo.com (G.Farsad Amanollahi) 
respect to the obligations of the company are essential. The process of simultaneous control of investment risk is known as optimization, which includes modelling, fuzzy logic genetic algorithm through the strategies related to portfolio, so that investors could achieve their financial goals by considering the existing limitations.

Portfolio optimization based on statistical models was firstly introduced by Markowitz (1952, 1959, 1991). It is a classical model for optimization and a basis for the modern theory of portfolio. Markowitz introduced six risk measures such as standard deviation, half variance, the expected loss, absolute deviation from the mean, probability of loss and the maximum loss. Levy (1984) showed that Markowitz's theory would not have the needed long-term efficiency so he raised the issue of diversification and suggested that investments in shares to be made in accordance with the rule of thumb. This rule considers time as the only effective factor in choosing how to invest and ignores the impact of other factors. Samuelson (1969) introduced a several period framework with discrete times. He used multi-period returning planning to model desirability in discrete time and maximizing the mathematical expectancy of this function and showed that optimum portfolios could gain a certain percentage of the capital by optimum investment in each period (regardless of the initial capital). Fisher and Weil (1971) offered a model based on Radyngton model (Shiu, 1990) by eliminating the assumption of yield curve flatness. Merton (1969) extended Samuelson model for continuous periods. A notable feature of Samuelson model is that it assumes if risk aversion is constant, the consumption and investment decisions would be independent. Jensen (1969) observed and approved some of the advantages of stochastic methods for modeling assets and debts.

\section{Variety of strategies for portfolio management}

Markowitz (1952) in his original model select the optimum portfolio based on the measure of efficiency and variance in assets' returns. Standard deviation and variance are measures of risk assuming that distribution of return rate is normal. He suggests that in addition to maximizing returns (as possible), investors want certain returns. If investors were only seeking to maximize expected returns, they could invest only on one type of asset with the highest expected return but this increases non-systematic risk. To justify this, it can be said that investors pay attention to both risk and return at the same time. So the investor trying to maximize the expected return and minimize uncertainty (i.e. risk) aims at these two conflicting objectives that must be balanced against each other. One of the interesting results of considering these two objectives is that the investor should diversify through purchasing several types of securities. Markowitz's approach in investment can be explained better, with more precise definition of the initial value and final value. Alexander and Baptista (2002) examined the economic, functional concept of Variance -Average to select the portfolio and compared Variance-Average and VaR-average. First they assumed that returns of assets follows the normal distribution. Then extended the results obtained to assets having abnormal distribution of returns and found out that for some risk averse investors the portfolio which has higher variance may have lower value at risk, hence it is possible that an efficient portfolio which minimizes the value at risk would not exist, but this does not mean that the variance is a more preferred measure of value at risk.

The aim of active portfolio management is to gain a balance between returns with a risk more than portfolio returns of passive index and net costs of transactions. Achieving this goal is not easy for managers. If the annual cost of transactions and fees is $1.5 \%$ of the value of portfolio assets, to achieve the same functionality as passive portfolio, the return of portfolio should be $1.5 \%$ more than passive portfolio. In addition, if the manager puts excessive weight to certain parts of the market in portfolio because of anticipated price increases, the risk of active portfolio will increase compared to passive portfolio. As a result, in order to cover higher efficiency, active portfolio return should be more than passive return. 


\section{Research Methodology}

In this study, using fuzzy numbers theory (Zadeh, 1965) and multi-objective decision making methods, we propose a model based on Markowitz's theory. Therefore, Markowitz basic model is developed by focusing on rate of return and we change it into fuzzy intervals by applying the principles of FMODM (Kahraman, 2008). Fuzzy logic can change qualitative concepts to quantitative ones by using linguistic variables. Because of these variables, we can quantify parameters such as good, fair, poor, etc. using fuzzy data and consider subjective judgment in decision making. As shown in Table 1 linguistic variables are on the basis of fuzzy numbers.

\section{Table 1}

Linguistic Variables and their Corresponding Fuzzy Numbers

\begin{tabular}{llll}
\hline Interval range & Linguistic variable & Fuzzy number & Confidence interval \\
\hline Negative returns & Very poor & $(0,0,1)$ & {$[\mathbf{0}, \boldsymbol{- \alpha}+\mathbf{1}]$} \\
$0-9$ & poor & $(0,1,3)$ & {$[\boldsymbol{\alpha}, \mathbf{- 2} \boldsymbol{\alpha}+\mathbf{3}]$} \\
$9-14$ & Relatively poor & $(1,3,5)$ & {$[\mathbf{2} \boldsymbol{\alpha}+\mathbf{1}, \mathbf{- 2} \boldsymbol{\alpha}+\mathbf{5}]$} \\
$14-18$ & average & $(3,57)$ & {$[\mathbf{2} \boldsymbol{\alpha}+\mathbf{3}, \mathbf{- 2} \boldsymbol{\alpha}+\mathbf{7}]$} \\
$18-23$ & Relatively good & $(5,7,9)$ & {$[\mathbf{2} \boldsymbol{\alpha}+5,-\mathbf{2} \boldsymbol{\alpha}+\mathbf{9}]$} \\
$23-32$ & good & $(7,9,10)$ & {$[\mathbf{2} \boldsymbol{\alpha}+\mathbf{7}, \mathbf{- 2} \boldsymbol{\alpha}+\mathbf{1 0}]$} \\
Above 32 & Very good & $(9,10,10)$ & {$[\boldsymbol{\alpha}+\mathbf{9 , 1 0}]$} \\
\hline
\end{tabular}

The above confidence intervals are obtained by using $\alpha$ fuzzy numbers cut $\left(a_{1}, a_{2}, a_{3}\right)$ and based on the following equation (Azar \& Faraji, 2008).

$\mathrm{A}^{\alpha}=\left[\mathrm{a}_{1}^{\alpha}, \mathrm{a}_{3}^{\alpha}\right]=\left[\left(\mathrm{a}_{2}-\mathrm{a}_{1}\right) \alpha+\mathrm{a}_{1}, \mathrm{a}_{3}-\left(\mathrm{a}_{3}-\mathrm{a}_{2}\right) \alpha\right]$

To model optimum portfolio selection problem, two objective functions and two constraints are considered as follows:

Expected return of each portfolio is considered as an ideal for investors. Therefore, maximizing the portfolio return, is an objective for investors. This objective can be shown as follows:

$\operatorname{Max} r_{p}=E\left(\sum_{i=1}^{N} x_{i} r_{i}\right)=\sum_{i=1}^{N} x_{i} E\left(r_{i}\right)$

In the above objectives function we have:

$\mathrm{r}_{\mathrm{p}}:$ portfolio returns

$\mathrm{r}_{\mathrm{i}}$ : returns of securities $i$

$\mathrm{x}_{\mathrm{i}}$ : percentage of investment funds that are invested in securities $i$.

The proposed study tries to minimize variance and covariance between different assets using the following objective function,

$\operatorname{Min} \operatorname{VAR}\left(\mathrm{r}_{\mathrm{p}}\right)=\sum_{\mathrm{i}=1}^{\mathrm{n}} \mathrm{x}_{\mathrm{i}}^{2} \operatorname{VAR}\left(\mathrm{r}_{\mathrm{i}}\right)+\sum_{\mathrm{j}=1}^{\mathrm{n}} \sum_{\mathrm{i}=1}^{\mathrm{n}} \mathrm{x}_{\mathrm{i}} \mathrm{x}_{\mathrm{j}} \operatorname{COV}\left(\mathrm{r}_{\mathrm{i}}, \mathrm{r}_{\mathrm{j}}\right)$

$\operatorname{VAR}\left(\mathrm{r}_{\mathrm{p}}\right)$ :variance of portfolio returns

$\operatorname{VAR}\left(\mathrm{r}_{\mathrm{i}}\right)$ :Variance of securities returns

$\operatorname{COV}\left(r_{i}, r_{j}\right)$ : covariance between the returns of securities $i$ and $j$

$\mathrm{x}_{\mathrm{i}}$ : the percentage of investment funds that are invested in securities $\mathrm{i}$. 
It should be noted that the following equation is used to calculate the covariance. $\operatorname{cov}\left(r_{i}, \quad r_{j}\right)=\frac{1}{m} \sum_{k=1}^{m}\left(\left[r_{i k}-E\left(r_{i}\right)\right]\left[r_{j k}-E\left(r_{j}\right)\right]\right)$,

where $m$ is the number of financial periods studied, $\mathrm{r}_{\mathrm{ik}}$ is the securities with rate $i$ in period $k$ and $\mathrm{r}_{\mathrm{jk}}$ is the security with rate $j$ in period $k$.

The first constraint is called budget constraint, which means that the total investment ratio in portfolio should be equal to 1 which is shown in the following equation:

$\sum_{i=1}^{n} x_{i}=1$

In addition, since short selling is prohibited in our investment strategy, we have

$\mathrm{x}_{\mathrm{i}} \geq 0$

This model can be summarized as follows:

$\max _{p}=E\left(\sum_{i=1}^{N} x_{i} r_{i}\right)=\sum_{i=1}^{N} x_{i} E\left(r_{i}\right)$

$\min \operatorname{VAR}\left(\mathrm{r}_{\mathrm{p}}\right)=\sum_{\mathrm{i}=1}^{\mathrm{n}} \mathrm{x}_{\mathrm{i}}^{2} \operatorname{VAR}\left(\mathrm{r}_{\mathrm{i}}\right)+\sum_{\mathrm{j}=1}^{\mathrm{n}} \sum_{\mathrm{i}=1}^{\mathrm{n}} \mathrm{x}_{\mathrm{i}} \mathrm{x}_{\mathrm{j}} \operatorname{COV}\left(\mathrm{r}_{\mathrm{i}}, \quad \mathrm{r}_{\mathrm{j}}\right)$

subject to

$\sum_{i=1}^{n} x_{i}=1$

$\mathrm{x}_{\mathrm{i}} \geq 0$

This model has two objective functions. Thus, investors face with a multi-objective decision problem (MODM). In this regard, if a minimum level (for example, $\mathrm{L}$ ) is defined for the return to prevent it getting less, the model will look like the following,

$\operatorname{Min} \operatorname{VAR}\left(\mathrm{r}_{\mathrm{p}}\right)=\sum_{\mathrm{i}=1}^{\mathrm{n}} \mathrm{x}_{\mathrm{i}}^{2} \operatorname{VAR}\left(\mathrm{r}_{\mathrm{i}}\right)+\sum_{\mathrm{j}=1}^{\mathrm{n}} \sum_{\mathrm{i}=1}^{\mathrm{n}} \mathrm{x}_{\mathrm{i}} \mathrm{x}_{\mathrm{j}} \operatorname{COV}\left(\mathrm{r}_{\mathrm{i}}, \quad \mathrm{r}_{\mathrm{j}}\right)$

subject to

$\sum_{i=1}^{N} x_{i} E\left(r_{i}\right) \geq L$

$\sum_{i=1}^{n} x_{i}=1$

$\mathrm{x}_{\mathrm{i}} \geq 0$

So far, we have introduced a model with crisp data, but the purpose of this research is to model in fuzzy situation. Hence considering that the rate of return in the future cannot be predicted correctly, we 
change them into fuzzy by using linguistic variables, and the other equations of this model are rewritten in regard to group data processing method according to fuzzy situation and the way numbers interact and applied in a model which is formulated based on fuzzy confidence intervals.

$$
\operatorname{Min} \operatorname{VAR}\left(\tilde{r}_{p}\right)=\sum_{i=1}^{n} x_{i}^{2}\left[\operatorname{VAR}^{-}\left(r_{i}\right)_{\alpha}, \operatorname{VAR}^{+}\left(r_{i}\right)_{\alpha}\right]+\sum_{i=1}^{n} \sum_{j=1}^{n} x_{i} x_{j}\left[\operatorname{COV}^{-}\left(r_{i}, r_{j}\right)_{\alpha}, \operatorname{COV}^{+}\left(r_{i}, r_{j}\right)_{\alpha}\right]
$$

Subject to

$$
\begin{aligned}
& \sum_{\substack{\mathrm{j}=1 \\
\mathrm{n}}}^{\mathrm{n}} \mathrm{x}_{\mathrm{j}}\left[\mathrm{E}^{-}\left(\mathrm{r}_{\mathrm{i}}\right)_{\alpha}, \mathrm{E}^{+}\left(\mathrm{r}_{\mathrm{i}}\right)_{\alpha}\right] \geq\left[\mathrm{L}_{\alpha}^{-}, \mathrm{L}_{\alpha}^{+}\right] \\
& \sum_{\mathrm{i}=1}^{\mathrm{n}} \mathrm{x}_{\mathrm{i}}=1
\end{aligned}
$$

$\mathrm{x}_{\mathrm{i}} \geq 0$

Model 1 can be divided into two separate models which are composed of two lower and upper confidence intervals above the confidence interval line parts written as follows:

$$
\min \operatorname{VAR}^{-}\left(\tilde{r}_{p}\right)=\sum_{i=1}^{n} x_{i}^{2} \operatorname{VAR}^{-}\left(r_{i}\right)_{\alpha}+\sum_{i=1}^{n} \sum_{j=1}^{n} x_{i} x_{j} \operatorname{COV}^{-}\left(r_{i}, r_{j}\right)_{\alpha}
$$

subject to

$$
\begin{aligned}
& \sum_{\substack{j=1 \\
n}}^{n} x_{j} E^{-}\left(r_{i}\right)_{\alpha} \geq L_{\alpha}^{-} \\
& \sum_{\substack{i=1 \\
x_{i} \geq 0}}^{n} x_{i}=1
\end{aligned}
$$

The considered model that is given below is the confidence interval line.

$$
\begin{aligned}
& \operatorname{Min} \operatorname{VAR}^{+}\left(\tilde{r}_{p}\right)=\sum_{i=1}^{n} x_{i}^{2} \operatorname{VAR}^{+}\left(r_{i}\right)_{\alpha}+\sum_{i=1}^{n} \sum_{j=1}^{n} x_{i} x_{j} \operatorname{COV}^{+}\left(r_{i}, r_{j}\right)_{\alpha} \\
& \text { subject to } \\
& \sum_{\substack{n \\
j=1}}^{n} x_{j} E^{+}\left(r_{i}\right)_{\alpha} \geq L_{\alpha}^{+} \\
& \sum_{i=1}^{n} x_{i}=1 \\
& x_{i} \geq 0
\end{aligned}
$$

\section{Research Hypotheses}

$\mathrm{H}_{1}$ : Fuzzy Logic has the ability to optimize portfolio.

$\mathrm{H}_{2}$ : Genetic algorithms has the ability to optimize portfolio.

$\mathrm{H}_{3}$ : The second hypothesis: genetic algorithm has the ability to optimize portfolio.

Each of the above models differs in the profit optimization portfolio.

In order to test the hypothesis of research data, 60 samples were selected among the companies which were active in Tehran Stock Exchange during 2012-2016. Also portfolios with 20 shares were formed 
to evaluate the effectiveness of fuzzy logic, genetic algorithms, hierarchical analysis and profits modeling.

\subsection{The first hypothesis test results}

The return rates of shares formed for portfolio exchange companies were converted according to fuzzy intervals using linguistic variables. Also variance and covariance were calculated and changed into two bottom-line and top-line models. Then the weight of each company was evaluated using logarithmic fuzzy preferences planning strategy. For this purpose, the necessary coding was done in Lingo software and ran for two models 2 and 3. After executing the code, the weight of each company was evaluated in accordance with Table 2.

\section{Table 2}

The weights calculated based on the implementation of the Lingo software

\begin{tabular}{llll}
\hline Share name & Weight & Share name & Weight \\
\hline Calcimin & 0.237 & Jam Petrochemicals & 0.226 \\
Iran Marine Industrial Company & 0.000 & Nirou Trans & 0.000 \\
Chadormalu & 0.284 & sadidpipe & 0.000 \\
Varziran & 0.000 & Esfahan steel & 0.000 \\
- & 0.000 & Iran Tractor Manufacturing & 0.000 \\
Gol Gohar & 0.127 & gazlouleh & 0.000 \\
Bojnourdcement & 0.000 & sepahangroup & 0.126 \\
Ngin coal & 0.126 & Tuka Rail & 0.000 \\
Marun Petrochemicals & 0.000 & System Group Co & 0.000 \\
Osvahpharma & 0.000 & Bojnourd Cement & 0.000
\end{tabular}

First hypothesis: fuzzy logic has the ability to optimize its portfolio. In order to test this hypothesis the chosen portfolio performance was compared with Sharp ratio for fuzzy logic with Sharp ratio derived from the Markowitz model using paired t-test. Portfolio sharp ratio in analytical hierarchy process (AHP) (Saaty, 1986) model and Markowitz model test results for the above hypothesizes are shown in Table 3.

Table 3

The comparison between Sharp ratio using AHP and Markowitz model

\begin{tabular}{llllll}
\hline Years & 2012 & 2013 & 2014 & 2015 & 2016 \\
\hline AHP Model & 1.34 & 2.73 & 2.53 & 2.45 & 3.22 \\
Markowitz Model & 0.35 & -0.15 & 1.76 & 1.87 & 2.07 \\
\hline
\end{tabular}

$\mathrm{H}_{0}$ : There is no significant difference between fuzzy logic model and Markowitz model portfolio`s annual Sharp ratio mean.

$\mathrm{H}_{1}$ : There is a significant difference between fuzzy logic model and Markowitz model portfolio`s annual Sharp ratio mean.

Paired test results for the above hypothesizes yields $\mathrm{t}$-value $=3.085$ with Sig. $=0.037$, which is meaningful when the level of significance is five percent. In other words, there is a significant difference between fuzzy logic model portfolio`s monthly Sharp ratio and Markowitz model portfolio`s monthly Sharp ratio. The proposed model's selected portfolio performed significantly better than Markowitz model based on the Sharp ratio from 2012 to 2014. Hence hypothesis 1 is not rejected.

\subsection{Second hypothesis `s test results}

To test the second hypothesis, genetic algorithm (Holland, 1992, Chen et al., 2011) is run based on the Markowitz model observing the stability of the algorithm, then the results of the optimum portfolio formation were evaluated using genetic algorithms. To do so, the run algorithm was iterated 10 times and the answers obtained from tests were compared. In Fig. 1, the genetic algorithm's efficient frontier 
in portfolio optimization can be seen. The risk and return of the genetic algorithm, are presented in Table 4.

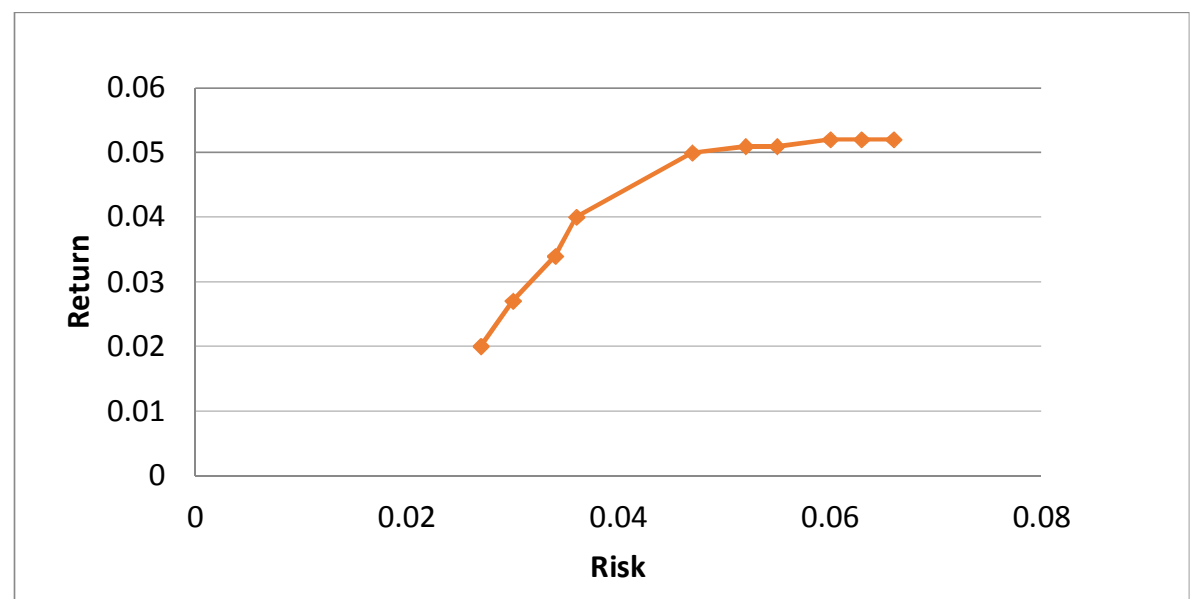

Fig. 1. The efficient frontier of portfolio optimization using genetic algorithms

Comparison of the efficient frontier derived from optimized portfolio formation using genetic algorithms, with risk-return curve shows the ability of genetic algorithms in optimization of the portfolio. Therefore the second hypothesis is rejected.

Table 4

The results of risk and return using genetic algorithm

\begin{tabular}{|c|c|c|c|c|c|c|c|c|c|c|}
\hline & 1 & 2 & 3 & 4 & 5 & 6 & 7 & 8 & 9 & 10 \\
\hline Return & 0.0044 & 0.0163 & 0.0198 & 0.0264 & 0.0290 & 0.0364 & 0.0381 & 0.0445 & 0.0506 & 0.0577 \\
\hline SD & 0.027 & 0.030 & 0.034 & 0.036 & 0.047 & 0.052 & 0.055 & 0.060 & 0.063 & 0.066 \\
\hline Variance & 0.0007 & 0.0009 & 0.0012 & 0.0013 & 0.0022 & 0.0027 & 0.0030 & 0.0036 & 0.0040 & 0.0044 \\
\hline
\end{tabular}

\subsection{Third hypothesis `s test results}

To test the effect of a fuzzy logic model a portfolio was used in which the three groups of twenty cases were tested. After using the linguistic variables to convert return rate of portfolio companies stocks to the fuzzy intervals they were used to obtain the weight of each of the company using Lingo software.

By comparison of Sharp ratio for fuzzy logic model with the Sharp ratio obtained from Markowitz model and in respect to the fact that significance value obtained is lower than significance value, it can be mentioned that the proposed model based on Sharp ratio performs significantly better than Markowitz model from years 2012 to 2016 for the selected portfolio. Therefore, we conclude that fuzzy logic has the ability to optimize the selected portfolio.

Genetic algorithm is used for portfolio optimization based on the Markowitz model. Financial ratio used in this method is stock return. The stability of the genetic algorithm, was examined for which similarity of the objective functions values, shows a good stability. Comparison of the efficient frontier of portfolio optimization using genetic algorithms with the risk-return curve, shows high efficiency of the algorithm to optimize portfolio. After ranking, the top stock holder was chosen to form the proposed model portfolios. By comparison of the Sharp ratio for the AHP model with the Sharp ratio derived from the Markowitz model using the $t$ test and with respect to the fact that the obtained significance value is lower than significance level, it can be mentioned that the proposed model based on Sharp ratio performed significantly better than Markowitz model from years 2012 to 2016 for the selected portfolio. So it is concluded that AHP has the ability for portfolio management. Financial profit modeling, has been carried out using four return on equity (ROE), return on assets (ROA), current ratio and quick ratio variables. In this model, in addition to examining stock optimization the, weighting to the criteria 
has been used. Sharp ratio to assess the optimum portfolio has been provided. According to the values of this ratio, it can be stated that profit financial modeling, has a good efficiency. It can be also seen, that these four models perform distinctly in terms of the portfolio formation but eventually all are able to optimize portfolio.

\section{Conclusion}

The aim of this study was comparative evaluation of the model in genetic algorithm fuzzy logic, hierarchical analysis and returns financial modeling for portfolio optimization over the period 2012-2016 for selected firms listed in Tehran Stock Exchange. The preliminary results have indicated that the proposed model was capable of locating efficient assets under uncertainty.

\section{References}

Alexander, G. J., \& Baptista, A. M. (2002). Economic implications of using a mean-VaR model for portfolio selection: A comparison with mean-variance analysis. Journal of Economic Dynamics and Control, 26(7), 1159-1193.

Alexander, S., Coleman, T. F., \& Li, Y. (2006). Minimizing CVaR and VaR for a portfolio of derivatives. Journal of Banking \& Finance, 30(2), 583-605.

Azar, A., \& Faraji, H. (2008). Fuzzy management science. Tehran: IMPSC.

Chen, Y., Mabu, S., \& Hirasawa, K. (2011). Genetic relation algorithm with guided mutation for the large-scale portfolio optimization. Expert Systems with Applications, 38(4), 3353-3363.

Fisher, L., \& Weil, R. L. (1971). Coping with the risk of interest-rate fluctuations: returns to bondholders from naive and optimal strategies. Journal of Business, 44(4), 408-431.

Holland, J. H. (1992). Genetic algorithms. Scientific American, 267(1), 66-72.

Jensen, M. C. (1969). Risk, the pricing of capital assets, and the evaluation of investment portfolios. The Journal of Business, 42(2), 167-247.

Kahraman, C. (Ed.). (2008). Fuzzy multi-criteria decision making: theory and applications with recent developments (Vol. 16). Springer Science \& Business Media.

Levy, H. (1984). Portfolio and investment selection: Theory and practice. Prentice Hall.

Markowitz, H. (1952). Portfolio selection. The journal of finance, 7(1), 77-91.

Markowitz H. (1959). Portfolio allocation. John Wiley \& Sons, Inc. New York. A Cowles Foundation Monograph.

Markowitz, H. M. (1991). Foundations of portfolio theory. The journal of finance, 46(2), 469-477.

Markowitz, H. M., \& Todd, G. P. (2000). Mean-variance analysis in portfolio choice and capital markets (Vol. 66). John Wiley \& Sons.

Merton, R. C. (1969). Lifetime portfolio selection under uncertainty: The continuous-time case. The review of Economics and Statistics, 247-257.

Roy, A.D. (1952). Safety First and the Holding of Assets. Econometrica, 20(3), 431-449.

Saaty, T. L. (1986). Axiomatic foundation of the analytic hierarchy process. Management science, 32(7), 841-855.

Samuelson, P. A. (1969). Lifetime portfolio selection by dynamic stochastic programming. The Review of Economics and Statistics, 51(3), 239-246.

Shiu, E. S. (1990). On Redington's theory of immunization. Insurance: Mathematics and Economics, $9(2-3), 171-175$.

Zadeh, L. A. (1965). Fuzzy sets. Information and control, 8(3), 338-353.

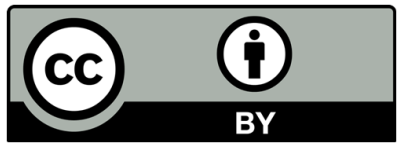

(C) 2017 by the authors; licensee Growing Science, Canada. This is an open access article distributed under the terms and conditions of the Creative Commons Attribution (CC-BY) license (http://creativecommons.org/licenses/by/4.0/). 